\title{
Impact of Social Capital on the Psychological Well-Being of Adolescents
}

\author{
Ayano Yamaguchi ${ }^{1}$ \\ ${ }^{1}$ College of Foreign Studies, Reitaku University, Kashiwa, Chiba, Japan \\ Correspondence: Ayano Yamaguchi, College of Foreign Studies, Reitaku University, 2-1-1 Hikarigaoka, \\ Kashiwa-shi, Chiba-ken 277-8686, Japan. Tel: 81-4-7173-3605. E-mail: ayamag13@reitaku-u.ac.jp
}

Received: March 29, 2013

Accepted: May 2, 2013 Online Published: May 21, 2013

doi:10.5539/ijps.v5n2p100

URL: http://dx.doi.org/10.5539/ijps.v5n2p100

\begin{abstract}
This study examines the impact of social capital and individual/family characteristics on the psychological well-being of 12- to 17-year-old adolescents in the United States. The data were provided by the National Survey of America's Families (NSAF). In order to examine the abovementioned effects, social capital as well as individual/family characteristics are included using ordinary least squares (OLS) regression models. The findings are important since empirical validation of the theoretical relationship between social capital and individual/family characteristics, as well as the psychological well-being of adolescents, is not found in the literature. The concept of social capital in the literature is only elaborated as having three distinct dimensions (bonding, bridging, and linking), which suggests that further research using measurement models should focus on these dimensions in order to explore whether a more precise relationship can be discovered.
\end{abstract}

Keywords: social capital, psychological well-being, mental health, supports, socialization, adolescence

\section{Introduction}

Social capital, as a relatively new concept in the fields of social epidemiology and health education research, has drawn much attention in recent years. The term "capital" is often used in economics to describe assets that can be invested in order to generate profits. The term "social capital" in health and behavior research can be defined as the sum of durable, trustworthy, reciprocal, and resource-rich network connections, which are used as an asset to empower a society and its members. Effective health education would benefit by addressing personally owned social capital in order to achieve targeted behavior changes. In the past decade, social capital has become a popular topic and research linking it with health and psychological well-being has become prevalent. Social capital has been considered as the web of cooperative relationships among citizens, which facilitates the resolution of collective action problems (Coleman, 1988) and features of social structure such as levels of interpersonal trust, norms of reciprocity, and mutual aid, which act as resources for such collective action (Coleman, 1988; Putnam, 1995, 2000). Social capital is generally considered to be the characteristics of social relationships rather than of individuals (Coleman, 1988), although the issue is a contentious one. Findings from previous studies in the health literature extensively discuss the positive association between social capital and psychological well-being of adolescents (Coleman, 1988; Dorsey \& Forehand, 2003; Furstenberg \& Hughes, 1995; Keating, 2000). However, only a few studies have focused on the psychological well-being of adolescents. Although factors in the social environment of adolescents, such as emotional and social development, are important in understanding their behaviors in social relationships or socialization, theoretical explanations have received far less attention. In social capital, the majority of research focuses more on individual aggregation and community. Social capital is positively related to psychological well-being (Coleman, 1988; Putnam, 1995, 2000). Although social capital mainly focuses on an adolescent's neighborhood, school, and community institutions, the social interactions that occur among various individuals in these social environments and settings are also important. The individuals in social capital influence social interactions by their individual characteristics (Veenstra, 2000). No consensus exists in the health research literature regarding the effect of social capital on either psychological well-being or the definition and measurement of social capital, making social capital a challenging issue. Therefore, social capital is a subject that may require further investigation. This study attempts to develop an empirical perspective on social capital that addresses psychological well-being while at least partially addressing definition and measurement issues. 
The main objective of this study is to propose and test a model as an empirical application that illustrates the process underlying the relationship between social capital and individual/family characteristics, as well as the psychological well-being of adolescents. First, it highlights the relationships between human capital (socioeconomic status measured by education and income, in particular) and self-rated health status, in addition to the psychological well-being among gender and age groups. Second, it explores the relationships between some human aspects of social capital (social and civic participation and the social-psychological constructs of trust, identity, and commitment, in particular) and self-rated health and psychological well-being before and after controlling sociodemographic and human capital effects. If a relationship exists between the human aspects of social capital/health and psychological well-being, then we have evidence of their compositional effect, especially if the relationship holds after controlling human capital effects. If few relationships of this type exist, then the challenge is renewed to find more intricate pathways through which trust in communities, for example, influences the overall health and psychological well-being.

\subsection{Psychological Well-Being}

In this study, psychological well-being is defined as emotional status or distress (e.g., symptoms of depression/anxiety) and problem behaviors (e.g., self-efficacy/coping). First, this study considers the importance of the negative outcomes of emotional status or distress as symptoms of depression and anxiety (Aneshensel, 2002). Second, it examines the importance of problem behaviors such as coping skills/self-efficacy, which supports the belief that through the exertion of control, one can influence the outcome of an individual's life events. The emotional and social development of coping skills/self-efficacy in adolescence is critical when helping adolescents maintain positive outcomes and promote higher psychological well-being (Compas, Connor-Smith, Saltzman, Thomsen, \& Wadsworth, 2001). Thus, psychological well-being provides not only a positive indicator of adolescent emotional and social development, but it is also a broad enabling factor that maintains optimal mental health. Moreover, psychological well-being is shown to be related to social factors.

\subsection{Individual and Family Characteristics}

In regard to the family income variable that is controlled, African Americans are found to have a slightly higher risk of depression compared to Caucasians. African Americans are also more likely than Caucasians to consider themselves as being in poor health (Dressler, 1993). Overall, adolescent health status is a good predictor of psychological well-being when controlling satisfaction variables such as job and family satisfaction, as well as social resource and demographic variables (Stones \& Kozma, 1986). During the early adolescent stage (10-14 years of age), adolescents often have intense friendships with peers and friends of their own gender, which usually result in one or two close friends. During the middle adolescent stage (15-17 years of age), peer and friend relationships become more group-oriented and often include both genders (Feldman \& Elliot, 1990). Finally, adolescent males are often seen as seeking autonomy and separation, while adolescent females strive toward greater interdependence and commitment (Sprinthall \& Collins, 1995).

In family characteristics, the relationship between family structure and income is part of a larger issue of whether parental absence itself reduces psychological well-being of adolescents or whether it is just a proxy for economic hardship. If economic hardship were the cause of marital dissolution, then one can conclude that family structure is not paramount when determining the outcome of adolescents. Indeed, financial hardship can contribute toward further family tension and disagreements between spouses, thus increasing the risk of marital dissolution. Studies in the United States and Great Britain showed that a lack of economic resources contributed toward divorce (O'Connor, Pickering, Dunn, \& Golding, 1999). This underscores the importance of examining the time order of events where economic deprivation contributes toward family transition instead of perceiving economic resources as a consequence of family change. It is equally important to investigate the direct effects of adolescent health as well as those of the intervening mechanisms on their development and psychological well-being. Conversely, if family disruption forces their circumstances into poverty, then family structure may indeed be harmful toward an adolescent's psychological well-being. This is mostly because family income is much higher in two-parent households and adolescents in two-parent families enjoy greater psychological well-being compared to their single-parent counterparts (Acock \& Demo, 1994). For living arrangements, while step-parent families are more financially sound compared to single-parent families, step-parent families still fall behind in relation to families led by biological parents (Thomson, Hanson, \& McLanahan, 1994). Finally, the mother's education also has a positive effect on the psychological well-being and socioemotional adjustment of adolescents in first-married families and continuously single-parent families (Hope, Power, \& Rogers, 1999). Parental mental health may well be the most important family influence. Since parental mental health can greatly affect how the parent interacts with the child, it ultimately creates higher levels of adolescent psychological well-being and positive health outcomes. Finally, employment for adolescents provides them with access to 
wider social networks and resource diffusion, which in turn, positively affects their mental health and psychological well-being (William, Takeuchi, \& Adair, 1992).

\subsection{Social Capital}

Coleman (1988) first suggests that social capital draws upon two main sociological theoretical frameworks: theories of social structure and community effects that address broader macro-level factors, and those of interaction and exchange that address interpersonal exchange and micro-level relationships. He believes that social capital is inherent in the social structure of relationships between actors and among actors, and stresses the importance of family and school systems as the most typical settings for investigating social capital. In addition, he views social capital in terms of the norms and social controls that must be understood and adopted in order to succeed. Cattell (2001) focused on two poor neighborhoods in East London and identified how social participation produced clear benefits in the overall psychological well-being. Factors such as church affiliation, perception of personal social support, and support within the neighborhood and its families were the most direct measures of social capital, which discriminated between the levels of functioning in children (Runyan, Hunter, Socolar, Amaya-Jackson, English, \& Landsverk, 1998). Putnam (1995) expands Coleman's (1988) social capital concept and framework and finds that networks in social capital play an important role in the provision of other aspects of social capital. He bases a large part of his influential work in Coleman's (1988) study, preserving the foci on action facilitated by social structure. On the basis of Coleman's (1988) definition of social capital in families and schools, Putnam (2000) extends the definition to apply it toward communities in general. His concept of social capital refers to a "collective asset" and a "common good" of neighborhoods and communities. Putnam (2000) introduces three dimensions of social capital: bonding, bridging, and linking. Bonding refers to interpersonal relationships and social support in relationships among relatively homogeneous groups (e.g., ethnic, religious, or socioeconomic), which strengthen the social ties within the particular group. Bridging refers to institutional relationships and social integration in relationships among heterogeneous groups, which strengthen the ties among such groups. Finally, linking refers to norms, solidarity, and reciprocity of community resources in relationships among individuals and groups from different social strata in a hierarchy in which power, social status, and wealth are accessed by the different groups. Thus, Putnam's (2000) three dimensions of social capital are used in this study.

\subsection{Contemporary Development of Social Capital on Psychological Well-Being}

Recent research on the psychological well-being of adolescents has received much attention (e.g., Keating, 2000; Coleman, 1988; Dorsey \& Forehand, 2003; Furstenberg \& Hughes, 1995), and the specific research connecting social capital to health outcomes via a social support mechanism is vast. In this sense, social capital is empirically linked to improved social development or socialization of adolescents (Keating, 2000). In addition, interpersonal interaction and social relationships are produced at the community level primarily through social integration of family members, which are positively related to psychological well-being (Coleman, 1988). Social capital for adolescents is also addressed in their neighborhood as well as their social and community institutions. Dorsey and Forehand (2003) find that one factor is more specific to the parents' own interpersonal networks: the availability of support the parent perceives from friends, coworkers, and neighbors. Furstenberg and Hughes (1995) offer the strongest study in support of the effects of interpersonal-level measures of social capital on young adults with a rich dataset collected longitudinally over the subjects' childhood and adolescence. However, their study is limited by the use of a small and nonrandom sample of adolescents born into poor, African-American single-parent households with teenage mothers. As Portes states, social capital performs functions as sources of family support and benefits through the extra-familial network (Portes, 1998). Several other studies show that close parent-child, peer, or teacher-student relationships and/or the experience of being bullied are associated with children of immigrants' life satisfaction (Wong, Chang, He, \& Wu, 2010), in addition to their psychological well-being (Ferguson, 2006).

\subsection{Research Question}

What impact does social capital have on the psychological well-being of 12- to 17-year-old adolescents in the United States?

\section{Method}

\subsection{Data and Sample}

This study is based on a secondary analysis and cross-sectional survey of data from the 1999 National Survey of America's Families (NSAF), obtained by the Urban Institute, which is a nonprofit and nonpartisan research center. These data from the NSAF are national representative of the civilian noninstitutionalized population 
under the age of 65 as well as their families. In addition, they include an oversampling of families with incomes $200 \%$ below the federal poverty level, which allows for detailed analyses of the subgroups of low-income families. The Most Knowledgeable Adult (MKA), the one adult in the household who is most knowledgeable about each child, answers questions about the family members' characteristics. For most children, the MKA is the child's biological mother. The NSAF based their information on a wide array of factors and characteristics related to the physical, economic, social, and psychological well-being of adolescents, children, and adults. In this study, the subjects included 1,490 adolescents $(52.3 \%$ male $(\mathrm{N}=779)$ and $47.7 \%$ female $(\mathrm{N}=711))$ from 12 to 17 years of age, which was the national estimate sample of the 1999 NSAF data. The data extensively sampled changing social trends, educational issues, and current policy issues for adolescents in the United States. This sample included Asian and Pacific Islanders (1.5\%, $\mathrm{N}=23)$, African Americans (12.5\%, $\mathrm{N}=186)$, Native Americans $(1.8 \%, \mathrm{~N}=27)$, and Caucasians $(84.2 \%, \mathrm{~N}=1254)$. The descriptive statistics for the data are reported in Table 1.

\subsubsection{Social Capital}

The social capital variable is measured by several factors that include whether adolescents receive help when they are angry or trying to prevent friends or family members getting into trouble; whether adolescents participate in any club or organization; and the availability of community resources where adolescents could go and receive help for issues such as criminal activity, domestic violence, pregnancy, and drugs/alcohol. The social capital variable ranges from 0 to 11, with the top score indicating that an adolescent has the highest levels of social capital. Conversely, a score of 0 means that the adolescent has the lowest levels of social capital. Finally, in order to get the reliability of social capital, Cronbach's alpha (a coefficient of reliability) is used, which includes a social capital of 0.96 .

\subsubsection{Psychological Well-Being}

The subjective standard of psychological well-being is measured by the Child Behavioral and Emotional Problem Scale (CBEPS) (Urban Institute, 1999), which includes the following six scale items: (a) does not get along with other peers; (b) cannot concentrate or pay attention for an extended amount of time; (c) has been unhappy, sad, or depressed; (d) has difficulty sleeping; (e) lies or cheats; and (f) performs poorly in school. The primary parent has three response choices: (a) often true $=1$, (b) sometimes true $=2$, and (c) never true $=3$. The responses are then totaled for a final score, which ranges from 6 to 18. The highest score of 18 represents an adolescent with the lowest levels of behavioral and emotional problems, which translates into a high level of psychological well-being. Conversely, a score of 12 or less represents an adolescent with high levels of behavioral and emotional problems, which translates into low levels of psychological well-being. Thus, this scale shows us something about the psychological adjustment or depression in adolescents, which uniquely affects aspects of their lives and the overall ability to manage them. Cronbach's alpha of CBEPS is 0.91 , which indicates a good internal reliability of the standard.

\subsubsection{Individual and Family Characteristics}

Family income, which is a constructed and continuous variable, compares income received during the year preceding the survey to the U.S. Census Bureau's federal poverty thresholds for that year. It includes the following scale: (a) less than 50\% above the poverty line (0.5); (b) 50\% and above, but less than $100 \%$ above the poverty line (1.0); (c) $100 \%$ and above, but less than $150 \%$ above the poverty line (1.5); (d) $150 \%$ and above, but less than $200 \%$ above the poverty line (2.0); (e) $200 \%$ and above, but less than $300 \%$ above the poverty line (3.0); and (f) $300 \%$ or more above the poverty line (4.0). Parental education is also a continuous measure based on the following: (a) parent completed the 8th grade; (b) parent completed the 9th, 10th, or 11th grade; (c) parent completed the 12th grade, but has no high-school diploma or GED; (d) parent has a GED; (e) parent has a high school diploma; (f) parent completed some vocational or technical classes, but has no certificate; (g) parent has a vocational or technical certificate; (h) parent completed some college classes, but has no college degree; (i) parent has an associate's degree; (j) parent has a bachelor's degree; (k) parent completed some graduate or professional classes, but has no graduate or professional degree; and (1) parent has a graduate or professional degree. Finally, parental mental health is a continuous measure that is captured using a 38-item scale adapted by the Urban Institute from the Mental Health Inventory (MHI-38) for its Medical Outcomes study (Urban Institute, 1999). This measure includes five scale items: (a) felt very nervous, (b) felt calm or peaceful, (c) felt downhearted and blue, (d) felt happy, and (e) felt so down in the dumps that nothing could cheer them up. The primary parent has four response choices: (a) all of the time $=1$, (b) most of the time $=2$, (c) some of the time $=$ 3 , and (d) none of the time $=4$. The responses are then totaled and multiplied by five for a final score ranging from 0 to 20 . On the basis of this scale, higher scores indicate better primary parent mental health and lower 
scores indicate a lower primary parent health status. Cronbach's alpha in this case is 0.94 , indicating good internal reliability of the standard.

The adolescents' employment status is a dichotomous variable, which is coded as adolescents who work or not. Adolescents who do not work are considered to be the baseline. The living arrangements of the adolescents are also coded into the following items: (a) live with no parents; (b) live with a single parent; (c) live in a blended/step family; or (d) live with a biological/adoptive family. In this case, the first category (where adolescents live with no parents) is used as the baseline. With respect to individual characteristics, the health status of adolescents is coded as: (a) poor, (b) fair, (c) good, (d) very good, and (e) excellent. The race/ethnicity variable is contained in four overall groups: Asian and Pacific Islanders, African Americans, Native Americans, and Caucasians (the baseline). Finally, the age variable ranges from 12 to 17 years of age and the gender variable is dealt with as a categorical variable where the male is the baseline.

\subsection{Data Analysis}

First, in order to discover the initial relationships regarding social capital, psychological well-being, and SES variables for 12- to 17-year-old adolescents in the United States, Pearson's product-moment correlations are utilized. Second, in order to more closely investigate the initial relationships, an ordinary least square (OLS) regression model is performed, which consists of social capital, individual, and family characteristic variables as predictors. The statistical influence of social capital in a broader context is included in the first model. After the first model is examined, family characteristics are included in the second model, followed by individual characteristics, which are included in the third and final model.

Table 1. Descriptive statistics regarding 12- to 17-year-old adolescents in the United States 1999 NSAF data (national estimate sample)

\begin{tabular}{ll}
\hline Variable & $\mathrm{N}=1490$ \\
& Mean/\%/SD \\
\hline Psychological well-being: CBPEB (Mean) & $15.65(\mathrm{SD}=3.13)$ \\
Social Capital (0-11score range) (Mean) & $2.36(\mathrm{SD}=10.42)$ \\
Family Characteristics & \\
Family Income (Last Year) (Mean) & $2.96(\mathrm{SD}=1.16)$ \\
Parental Education (Mean) & $7.00(\mathrm{SD}=3.26)$ \\
Parental Mental Health (Mean) & $15.57(\mathrm{SD}=3.41)$ \\
Adolescents' Employment (Percent) & 34.0 \\
Adolescents' Living Arrangements (Mean) & $3.23(\mathrm{SD}=1.12)$ \\
Individual Characteristics & \\
Adolescents' Health Status (Mean) & $4.27(\mathrm{SD}=0.89)$ \\
Ethnicity (Percent) & \\
Asians and Pacific Islanders & 1.5 \\
African Americans & 12.5 \\
Native Americans & 1.8 \\
Caucasians (Baseline) & 84.2 \\
Age (Mean) & $14.6(\mathrm{SD}=1.76)$ \\
Male (Baseline) (Percent) & 52.3 \\
Female (Percent) & 47.7 \\
\hline
\end{tabular}

\section{Results}

Pearson's product-moment correlations provide important preliminary information regarding the interrelationships among social capital, psychological well-being, and SES variables for 12- to 17-year-old adolescents in the United States. Overall, all these relationships are significant at the 0.01 level. As initial 
relationships, especially, there is a positive and strong correlation between social capital and the psychological well-being of the adolescents in this sample $(b=0.61, p<0.01)$. There is also a positive and strong correlation between the parental mental health and psychological well-being of these adolescents $(b=0.57, p<0.01)$ as well as the parental mental health and social capital $(b=0.57, p<0.01)$. Moreover, there is a positive correlation between adolescent's health status and psychological well-being $(b=0.24, p<0.01)$ as well as the adolescents' health status and social capital $(b=0.06, p<0.01)$.

Table 2. Correlations for Psychological well-being (CBEPS) and independent variables

\begin{tabular}{|c|c|c|c|c|c|c|c|c|c|c|c|c|c|}
\hline & 1 & 2 & 3 & 4 & 5 & 6 & 7 & 8 & 9 & 10 & 11 & 12 & 13 \\
\hline 1 & 1 & & & & & & & & & & & & \\
\hline \multicolumn{14}{|l|}{ Psychological } \\
\hline \multicolumn{14}{|l|}{ well-being } \\
\hline 2 Social & $0.614 * *$ & 1 & & & & & & & & & & & \\
\hline \multicolumn{14}{|l|}{ Capital } \\
\hline 3 Family & $0.175^{* *}$ & $0.094^{* *}$ & 1 & & & & & & & & & & \\
\hline \multicolumn{14}{|l|}{ Income } \\
\hline 4 Parental & $0.199 * *$ & $0.208^{* *}$ & $0.378^{* *}$ & 1 & & & & & & & & & \\
\hline \multicolumn{14}{|l|}{ Education } \\
\hline 5 Parent & $0.573^{* *}$ & $0.572 * *$ & $0.229 * *$ & $0.213^{* *}$ & 1 & & & & & & & & \\
\hline \multicolumn{14}{|l|}{ Mental Health } \\
\hline 6 Adolescents' & $0.051^{*}$ & -0.005 & $-0.061^{*}$ & -0.016 & -0.026 & 1 & & & & & & & \\
\hline \multicolumn{14}{|l|}{ Employment } \\
\hline 7 Adolescents' & $0.157^{* *}$ & 0.032 & $0.321^{* *}$ & $0.141 * *$ & $0.152^{* *}$ & $-0.052^{*}$ & 1 & & & & & & \\
\hline \multicolumn{14}{|l|}{ Living } \\
\hline \multicolumn{14}{|l|}{ Arrangements } \\
\hline 8 Adolescents' & $0.242^{* *}$ & $0.064^{*}$ & $0.229 * *$ & $0.206^{* *}$ & $0.196^{* *}$ & $-0.077 * *$ & $0.150^{* *}$ & 1 & & & & & \\
\hline \multicolumn{14}{|l|}{ Health Status } \\
\hline 9 & 0.026 & 0.006 & 0.044 & 0.030 & 0.032 & 0.026 & 0.018 & -0.007 & 1 & & & & \\
\hline \multicolumn{14}{|l|}{ Asians/Pacific } \\
\hline \multicolumn{14}{|l|}{ Islanders } \\
\hline 10 African & -0.015 & -0.008 & $-0.209^{* *}$ & $-0.104 * *$ & -0.022 & $0.097 * *$ & $-0.246^{* *}$ & $-0.157^{* *}$ & -0.047 & 1 & & & \\
\hline \multicolumn{14}{|l|}{ Americans } \\
\hline 11 Native & 0.002 & 0.007 & $-0.053^{*}$ & 0.017 & -0.009 & 0.014 & -0.046 & -0.018 & -0.017 & $-0.051^{*}$ & 1 & & \\
\hline \multicolumn{14}{|l|}{ Americans } \\
\hline $12 \mathrm{Age}$ & -0.022 & -0.019 & 0.044 & 0.001 & 0.006 & $-0.219^{* *}$ & 0.024 & -0.025 & -0.037 & 0.031 & -0.035 & 1 & \\
\hline 13 Gender & 0.046 & -0.013 & 0.025 & 0.009 & 0.010 & -0.013 & 0.023 & 0.040 & -0.043 & 0.025 & -0.039 & 0.003 & 1 \\
\hline
\end{tabular}

$* \mathrm{p}<0.05, * * \mathrm{p}<0.01$

Although this study found positive and strong correlations as preliminary relationships, causation is questionable. Thus, in order to investigate causation, an OLS regression model was conducted on psychological well-being among the adolescents in this sample, as shown in Table 3. Model 1 shows that social capital $(b=0.20, p<0.01)$ is positively significant; $38 \%$ of the explained variance of psychological well-being among these adolescents is accounted for. Model 2 shows that social capital $(b=0.13, p<0.01)$, parental mental health $(b=0.28, p<0.01)$, adolescents' employment $(b=0.28, p<0.01)$, and adolescents' living arrangements $(b=0.24, p<0.01)$ are positively significant. Only $9 \%$ of the explained variance increases marginally, as compared to the first model. Model 3 shows that social capital $(b=0.13, p<0.01)$, parental mental health $(b=0.25, p<0.01)$, adolescents' employment $(b=0.31, p<0.01)$, adolescents' living arrangements $(b=0.23, p<0.01)$, adolescents' health status $(b=0.54, p<0.01)$, and gender $(b=0.26, p<0.05)$ are positively significant. Only $2 \%$ of the explained variance increased marginally, as compared to the second model. 
Table 3. OLS regression of unstandardized coefficients for social capital on psychological well-being (CBEPS) in 1999 NSAF data

\begin{tabular}{llll}
\hline Variables & Model 1 & Model 2 & Model 3 \\
\hline Social Capital (0-11 score range) & $0.20^{* *}$ & $0.13^{* *}$ & $0.13^{* *}$ \\
Family Characteristics & & & \\
Family Income & 0.10 & 0.05 \\
Parental Education & 0.20 & 0.00 \\
Parental Mental Health & $0.28^{* *}$ & $0.25^{* *}$ \\
Adolescents' Employment & $0.28^{* *}$ & $0.31^{* *}$ \\
Adolescents' Living Arrangements & $0.24^{* *}$ & $0.23^{* *}$ \\
Individual Characteristics & & \\
Adolescents' Health Status & & $0.54^{* *}$ \\
Asians and Pacific Islanders & & 0.39 \\
African Americans & & 0.34 \\
Native Americans & & 0.29 \\
Age & & 0.00 \\
Gender (Baseline $=$ Male, 1) & & $0.26^{*}$ \\
R-Square & & .47 \\
\hline *05, **p $<0.01$. & .38 &
\end{tabular}

\section{Discussion and Conclusion}

The primary focus of this study is to examine the empirical validation of social capital in order to understand the psychological well-being of adolescents in the United States. Using a sample of 1,490 mostly low-income adolescents, the model completes a reasonable task in predicting psychological well-being. The results underscore important aspects of the hazards faced by adolescents and the social resources available. Social capital makes a significant contribution toward psychological well-being among the adolescents in this sample, and in general, its significant forms include sharing negative or positive feelings with family, friends, or coworkers; talking with parents, friends, or coworkers about personal problems; and having parents around (Coleman, 1988). On the basis of these forms, the more supportive the environment becomes, the more participation in any available community resources. As a result, it leads toward fewer depressive symptoms and better psychological well-being. What is important about this initial finding is that it provides parents, friends, and coworkers with a very direct and manageable strategy for improving the psychological well-being of their adolescents. In addition, if adolescents possess enough social capital, they are more likely to have better health status. Moreover, higher levels of psychological well-being for adolescents may be due, in part, to their parents' greater emotional stability and protection. These adolescents are more likely to talk with their parents, friends, or coworkers about any feelings and problems that they may have. Originally, social capital provided important opportunities for adolescents to easily obtain or access social resources from interpersonal to community levels developed through relationships (e.g., bonding, bridging, and/or linking social capital). However, social capital also helped to improve emotional or social development of adolescents through "features of social organization, such as networks, norms, and social trust, which facilitate coordination and cooperation for mutual benefit" (Putnam, 1995, p. 67). Increasing social capital can lead to beneficial effects and better psychological well-being, as well as better communication and greater long-term academic achievement (Coleman, 1988).

In order to explain the significant mechanism of social capital, three dimensions of social capital (Putnam, 1995) are used in this study: bonding, bridging, and linking. Bonding may contribute in that adolescents take advantage of the opportunities to build and access potential social resources, and expand them through their interpersonal relationships (e.g., friends, parents, and coworkers) with respect to their emotional and social development. Bridging may contribute in that adolescents take advantage of the opportunities to build and access social resources such as strengthening weak ties or social integration through institutional relationships, and expanding them through their institutional relationships with respect to emotional or social development. Finally, linking 
may contribute in that adolescents take advantage of the availability of community resources, which is found to play an important role in high levels of psychological well-being. The availability of community resources is important. For example, if an adolescent lives in a community with a program targeting pregnancy, drugs, or crime, he or she is more likely to have a higher level of psychological well-being because of the educational effects of these programs. These community resources indicate that community-based factors may have benefits in addition to interpersonal interaction and networking. These findings show that these community programs have multiple-level benefits for adolescents because they have macro-level community-level effects, opportunities for linking social capital, and services specifically tailored toward adolescent issues.

Finally, the association between social capital and psychological well-being for adolescents differs in specific family SES in regard to individual and family characteristics. The findings of this study may suggest that family structure effects are quite apparent for the psychological well-being of adolescents. This is consistent with previous research which showed that divorce-related stressful events are positively associated with lower psychological well-being as well as internalizing and externalizing behaviors for adolescents (Thomson, Hanson, \& McLanahan, 1994). In contrast, living in a biological/step family may be positively associated with better psychological well-being for both parents and adolescents. Divorce can indeed have severe consequences for the economic situation of mothers, which then increases the propensity for hostile parenting. As the results demonstrate, this can contribute toward depressed behavior and low levels of psychological well-being in adolescents. If family structure persists, even when we account for economic resources and family processes, then structure per se is indeed an important determinant of psychological well-being. Finally, if adolescents are employed, they take advantage of information and social resources by using even wider social networks (William, Takeuchi, \& Adair, 1992), which positively influence their health status and psychological well-being (George \& Landerman, 1984).

In conclusion, this study examined the impact of social capital and individual/family characteristics on the psychological well-being of 12- to 17-year-old adolescents in the United States. The data were based on the 1999 National Survey of America's Families (NSAF). Although the causality is questionable, the findings are important since the empirical validation of the theoretical relationship between social capital and individual/family characteristics, as well as the psychological well-being of adolescents, is not found in the literature. In addition, individual/family characteristics in regard to psychological well-being have not been found in previous research (Coleman, 1988; Putnam, 1995). However, especially since the concept of social capital is elaborated as including Putnam's three distinct dimensions (bonding, bridging, and linking) (1995), further research using measurement models that focus on these dimensions is necessary in order to discover a more precise association. The potential significance of studying how psychological well-being for adolescents may be greatly associated to the extent to which the individual has access to social resources as well as the knowledge to access the three dimensions of social capital (Putnam, 1995). Finally, it would be even more useful and helpful when assisting adolescents with a low level of psychological well-being.

This study contributes toward the understanding of adolescent social capital (Coleman, 1988; Putnam, 1995). First, of the few studies on social capital related to the psychological well-being of adolescents, the majority utilize small, nonrandom samples of adolescents. Second, the major findings are representative of the national estimate sample for adolescents and include a wide range of backgrounds and characteristics. Third, this study tested several social capital indicators. The major findings also address how individual social capital (Coleman, 1988) for adolescents is important for the psychological well-being of their social relationships and social/emotional development. For example, according to Coleman (1988), the social interactions for adolescents that occur with various individuals in these social settings are important. As the results show, individual social capital affects social interactions through adolescent individual characteristics or personal traits (Coleman, 1988). Finally, unique to this study is the fact that attention is given to the accumulation of social capital and individual/family characteristics of the adolescents. This study also supports major findings on the importance of their own social relationships in addition to their emotional and social development. As adolescents make the transition toward adulthood, social capital may be important when obtaining additional social capital as they become increasingly more in control of their socially controlled world relationships and futures (Coleman, 1988).

\section{Limitations and Future Directions}

Some limitations in this study must be carefully considered. The research design is cross-sectional, which limits its ability to discern causal relationships. Causality can be implied, but not confirmed. Although the causality is questionable, this study shows the strong relationship between social capital and the psychological well-being of adolescents. Further research suggests that a longitudinal study needs to be developed if $38.0 \%$ of the explained 
variance is that persistent over time. It also suggests that more policy research is needed, which requires involvement by community organizations for adolescents (such as schools) as well as fiscal and organizational investment from given social capital influences. For example, the role of adolescent social capital shows that more institutional or community resources should provide assistance with academic-related tasks in order to enhance the overall school experience of its adolescents. In this case, services such as tutoring or mentoring may need to be widely encouraged and publicized.

Secondary data analysis was used in this study as the quantitative method, but primary data such as questionnaires (Fitzpatrick, Piko, Wright, \& LaGory, 2005) and additional qualitative data (Morrow, 2001) may provide even more information about the various strategies and values of social capital on the psychological well-being of adolescents within the social context. In order to reinforce the findings of survey data and view whether the survey reports converge with the conduct and feelings of the individual respondents, a qualitative method should be used in further research. With regard to measurement error, the social capital standards were limited by primarily looking at the availability and access to social capital in social environments or settings where social relationships or socializations have the potential of development. Therefore, with primary data such as those collected on questionnaires, further research should expand the indicators of social capital and address its critical limitations. In social capital, the quantity of these relationships is important because an increase in social capital is argued to cause an increase in opportunities and positive development for adolescents. However, the number of individuals and interactions involved shows little about the quality of interaction. Thus, models should also be extended to include measures of capturing information on actual relationships, networks, and their qualities.

\section{Implications}

This study suggests that social capital will indeed work for various individuals and neighborhoods even though the results may vary. What is clear from this study, however, is that social capital is important for maintaining the psychological well-being of adolescents. Neighborhood associations can benefit from this knowledge by reaching out and encouraging the development and maintenance of social integration and ties (Coleman, 1988; Putnam, 1995). Further research will be necessary in order to examine cross-cultural similarities and differences for individual behaviors in terms of how to take advantage of the social capital for individual and family characteristics.

\section{Acknowledgements}

This research was supported by the Grant-in-Aid for Young Scientists B and the Japan Science Technology (JST) Agency, Japan. This article is based on portions of the first author's doctoral course paper, conducted under the supervision of Prof. D. William Wood, Prof. Emeritus, Eldon L. Wegner, Professor Yean-Ju Lee, Prof. Emeritus Kiyoshi Ikeda, and Prof. Min-Sun Kim. I thank them all for their helpful advice and for providing insightful suggestions and comments on an earlier version of this manuscript. Also, I gratefully acknowledge the National Survey of America's Families (NSAF) for providing useful data.

\section{References}

Acock, A., \& Demo, D. (1994). Family diversity and psychological well-being. Thousand Oaks, CA: Sage.

Aneshensel, C. S. (2002). Commentary: Answers and questions in the sociology of mental health. Journal of Health and Social Behavior, 43, 236-246. http://dx.doi.org/10.2307/3090199

Cattell, V. (2001). Poor people, poor places, and poor health: The mediating role of social networks and social capital. Social Forms, 70, 1077-1100.

Coleman, J. S. (1988). Social capital in the creation of human capital. American Journal of Sociology, 94 , S95-S120. http://dx.doi.org/10.1086/228943

Compas, B., Connor-Smith, J., Saltzman, H., Thomsen, A. H., \& Wadsworth, M. E. (2001). Coping with stress during childhood and adolescence: Problems, progress, and potential in theory and research. Psychology Bulletin, 127, 87-127. http://dx.doi.org/10.1037/0033-2909.127.1.87

Dorsey, S., \& Forehand, R. (2003). The relation of social capital to child psychosocial adjustment difficulties: The role of positive parenting and neighborhood dangerousness. Journal of Psychopathology and Behavioral Assessment, 25(1), 11-23. http://dx.doi.org/10.1023/A:1022295802449

Dressler, W. W. (1993). Health in the African American community: Accounting for health inequalities. Medical Anthropology Quarterly, 7, 325-345. http://dx.doi.org/10.1525/maq.1993.7.4.02a00030

Feldman, S. S., \& Elliot, G. R. (Eds.). (1990). At the threshold: The developing adolescent. Cambridge: Harvard 
University Press.

Ferguson, K. M. (2006). Social capital and children's psychological well-being: A critical synthesis of the international social capital literature. International Journal of Social Welfare, 15, 2-15. http://dx.doi.org/10.1111/j.1468-2397.2006.00575.x

Fitzpatrick, K. M., Piko, B. F., Wright, D. R., \& LaGory, M. (2005). Depressive symptomatology, exposure to violence, and the role of social capital among African American adolescents. American Journal of Orthopsychiatry, 75(2), 262-274. http://dx.doi.org/10.1037/0002-9432.75.2.262

Furstenberg, F. F., \& Hughes, M. E. (1995). Social capital and successful development among at-risk youth. Journal of Marriage and the Family, 57, 580-592. http://dx.doi.org/10.2307/353914

George, L. K., \& Landerman, R. (1984). Health and subjective psychological well-being: A replicated secondary analysis. International Journal of Aging and Human Development, 19, 133-156. http://dx.doi.org/10.2190/FHHT-25R8-F8KT-MAJD

Hope, S., Power, C., \& Rogers, B. (1999). Marital status traditions and psychological distress: Longitudinal evidence from a national population sample. Psychological Medicine, 29, 381-389. http://dx.doi.org/10.1017/S0033291798008149

Keating, D. P. (2000). Social capital and developmental health: Making the connection. Journal of $\begin{array}{llll}\text { Developmental and } \quad \text { Behavioral } & \text { 21(1), }\end{array}$ http://dx.doi.org/10.1097/00004703-200002000-00009

Morrow, V. (2001). Using qualitative methods to elicit young people's perspectives on their environments: Some ideas for community health initiatives. Health Education Research, 16(3), 255-268. http://dx.doi.org/10.1093/her/16.3.255

O’Connor, T. G., Pickering, K., Dunn, J., \& Golding, J. (1999). Frequency and predictors of relationship dissolution in a community sample in England. Journal of Family Psychology, 13, 436-449. http://dx.doi.org/10.1037/0893-3200.13.3.436

Portes, A. (1998). Social capital: Its origins and applications in modern sociology. Annual Review of Sociology, 24, 1-24. http://dx.doi.org/10.1146/annurev.soc.24.1.1

Putnam, R. D. (1995). Bowling alone: America's declining social capital. Journal of Democracy, 6, 65-78. http://dx.doi.org/10.1353/jod.1995.0002

Putnam, R. D. (2000). Bowling alone: The collapse and revival of American community. New York: Simon and Schuster.

Runyan, D. K., Hunter, W. M., Socolar, R. R. S., Amaya-Jackson, L., English, D., \& Landsverk, J. (1998). Children who prosper in unfavorable environments: The relationship to social capital. Pediatrics, 101, 12-18. http://dx.doi.org/10.1542/peds.101.1.12

Sprinthall, N. A., \& Collins, W. A. (1995). Adolescent psychology: A developmental Review (3rd ed,). New York: McGraw Hill.

Stones, M. J., \& Kozma, A. (1986). Happy are they who are happy: A test between two causal models of relationships between happiness and its correlates. Experimental Aging Research, 12, 23-29. http://dx.doi.org/10.1080/03610738608259431

Thomson, E., Hanson, T., \& McLanahan, S. (1994). Family structure and child psychological well-being: Economic resources vs. parental behavior. Social Forces, 73(1), 221-242.

Urban Institute. (1999, March). Benchmarking child and family psychological well-being measures in the NSAF (Report No. 6). Washington, DC: Author.

Veenstra, G. (2000). Social capital, SES and health: An individual-level analysis. Social Science and Medicine, 50, 619-629. http://dx.doi.org/10.1016/S0277-9536(99)00307-X

William, D. R., Takeuchi, D. T., \& Adair, R. T. (1992). Socioeconomic status and psychiatric disorder among blacks and whites. Social Forces, 71, 179-194.

Wong, D. F. K., Chang, Y. L., He, X. S., \& Wu, Q. B. (2010). The protective functions of relationships, social support and self-esteem in the life satisfaction of children of migrant workers in Shanghai, China. The International Journal of Social Psychiatry, 54(2), 143-157. http://dx.doi.org/10.1177/0020764009102755 